\title{
Comparison of Two Locally Made Motorized Plantain Slicers
}

\author{
Adedipe J.O' ${ }^{1}$, Owoloja A.O ${ }^{2}$, Afolabi R.T ${ }^{3}$, Adedipe $D^{4}$, Ekaun A.A ${ }^{5}$, Olatunji B.T ${ }^{6}$, Ajiboye O.O $^{7}$ \\ 1,2,3,4,5,6,7 Forestry Research Institute of Nigeria
}

\begin{abstract}
This study focused on comparing two locally designed plantain slicers in other to economically and productively advice small scale chips - producers. The two selected slicing machines were horizontally inclined slicer (HIS) and vertically inclined slicer (VIS). These slicers were carefully chosen and it was ensured they had same power input, motor speed, and slicing blade of equal length. Evaluation result showed that the highest throughput capacity for HIS was $51.16 \mathrm{~kg} / \mathrm{hr}$ and had an average throughput capacity of $50.10 \mathrm{~kg} / \mathrm{hr}$ while the highest throughput capacity for VIS was $45.90 \mathrm{~kg} / \mathrm{hr}$ and had an average throughput capacity of $45.34 \mathrm{~kg} / \mathrm{hr}$. The results of the slicing efficiencies showed that a maximum efficiency of $100 \%$, but had an average efficiency value of $92.84 \%$, while VIS had a maximum efficiency value of $87 \%$ and an average efficiency value of $83.25 \%$. From the results of the throughput capacity and the efficiency of the two slicers, it can be concluded that HIS performed better and faster than VIS and is considered the better both economically and productively.
\end{abstract}

KEYWORDS: VIS, HIS, Slicer, Throughput, Efficiency.

\section{INTORDUCTION}

Plantain (Musa paradisica L) is a popular staple in Africa and in many other countries of the world. Plantain is taken in various forms such as fried plantain, boiled plantain, roasted plantain, baked plantain, and plantain chips. It can also be processed via slicing, drying and grinding for production of plantain flour which is also consumed when baked. There is high demand for plantain slices in form of fried plantain chips by travelers, office workers, school children, and families as part of breakfast. In an effort to make it readily available, several means have been devised in slicing plantain into pieces which is further processed into chips, flour, baked or fried. Plantain is commonly produced in West Africa especially Cameroon, Benin, Ghana and Nigeria; (FAO, 1990) when ripe plantain is fried, it is generally called dodo (dough-dough). In Ikire, a town in western Nigeria, there is a unique and special way of preparing plantain chips which are popularly called 'Dodo Ikire', this product is made from overripe plantain. The locally made product (dodo Ikire) has a preservative quality that last up to two months without refrigeration (IITA, 2001). Provision of a motorized slicing machine contributes to food security, export earnings and economic growth. Farmers are faced with post-harvest losses since the plantain perish or get rotten easily when ripe, for this reason, many methods of processing (roasting and frying) are being introduced to reduced losses for human consumption, after harvest. Commonly, the process of manual peeling and slicing using knife is time consuming (Awoluyi, 2008; Obeng, 2004). Traditional slicing methods do not support large quantity slicing of plantain, especially for commercial purposes. And it is observed that plantain slice is mainly done by hand. Hand slicing takes a lot of time, and it is observed that when cutting or slicing the plantain it is not equal [not the same size] some will be big while some are small. The common methods of slicing plantain in our localities today include the use of knife, wooden platform plantain slicer, plastic with metal cutter and existing slicing machine. These methods have a lot of deficiencies in terms of slicing time, efficiency, productivity, quality and safety.

The manually operated wooden platform plantain slicer is a slow method commonly used in small scale industries as reported by Okafor (2013). This is why the use of mechanized slicer is very necessary to reduce the drudgery of continuous cutting of bulk of plantains and potatoes with knife. The use of motorized slicer will facilitate mass production of the chips. The plantain is pressed and moved across the sharp blades of the machine. The machine operator is endangered by getting his finger cut by the exposed sharp blades when the slicing misses a cut (Okafor, 2013).It is also time consuming since the operator will be operating a slow rate to avoid injury. Nwanekezie and Ukagu (1999) reported another manually operated cutting knife in which the plantain is placed on top of a sharp blade on the base frame of the machine and the upper handle which also contain sharp blade is pressed down thereby slicing the tuber into chips. The operator gets his hands injured when unloading, because some of the chips stocked in between the sharp blades. These also consume time because of the slow nature in unloading in order to avoid injury. Designing and fabricating a motorized plantain slicer reduced drudgery and increased the rate and volume of slice at a particular time. Banana slicing machine is used for slicing banana plain and rippled chip, peeled 


\section{"Comparison of Two Locally Made Motorized Plantain Slicers"}

bananas are fed manually from the top of the slicer and sliced chips are guided through a guide. It is a hand push machine in which the outlet is mounted over a frying pan. The machine is a single pulley driven shape of slices elliptical about 2$3 \mathrm{~mm}$ size. It requires low maintenance and easy handling. The machine is provided with cutting plate which has adjustable blade and the machine frame is fabricated in stainless steel (FIIRO, 2008). It was observed that the traditional method of cutting plantains into chips is stressful leading to drudgery and prone to finger injury, time consuming, does not produce uniform size of sliced chips, and inevitably leads to low output by farmers with little or no income margin. The invention of different motorized plantain slicers have helped solve many slicing problems especially among low-scale chips producers. One notable challenge presently is the most economical and productive design to enhance their business.

\section{MATERALS AND METHOD Materials}

Materials used for this study were collected from small scale plantain-chips producers in Ibadan, Oyo-State, Nigeria. A vertically aligned slicing chamber and a horizontally inclined slicing chamber were collected. The two different designs were used to slice plantain. The performance of each was evaluated using different parameters they were compared.

\section{Selection Consideration \\ Selection Criteria}

Some factors were considered in the selection of the plantain slicing machines in order to have a qualitative and critically balanced comparison

- Hygiene ... the slicing blades of selected designs must be washable so that quality chips can be obtained therefore the blade must be made of stainless steel

- Acceptable Color ... the color of the sliced products must not change, though it depends on the color of the plantain to be sliced.

- Aesthetics ... the machine physical appearance should look good, attractive and acceptable

- Size and weight of the machine ... the overall size and weight of the machine is an important factor that governs the size of the selected materials and their components such as electric motor. The easy movement of the machine is an important factor, so that anywhere the machine will be needed, it can be easily conveyed to the place.

- Compactness ... is important when the machine is built as small as possible without removing basic components and features.

- Ease of Operation ... the machine is designed in a way that it is easy to assemble, disassemble, load, operate and off-load. - Safety ... the wires of the electric motor are all insulated and the electrical switch is carefully selected to ensure complete power cut from the mains when switch off and to prevent electric shock in case the neutral wire becomes the live when plugged to a wrongly connected socket. The casing on the electric motor was also insulated, while sharp edges were made blunt. Rotating parts were also shielded.

- Ease of Maintenance ... the machine must also be easily maintained either by routine or weekly cleaning, retightening of bolts, and lubrication of necessary parts, for example, bearing and joints to ensure that the machine does not get wet after the plantain has been sliced in order to prevent rusting of the moving parts.

\section{Functional requirement}

1. Would be able estimate the quantity of plantain chips produced.

2. To save time while performing a cutting operation on plantain

3. To help increase the rate of production

The machine components peculiar to the two slicing machines selected for the study include:

- Cone (pulp)

- Slicing blade

- Collection tray

- Switch

- Electric motor and capacitor

- Framework

\section{Description of machine components}

The plantain slicers were designed to work on the principle of shearing or slicing, due to the sudden contact from the rotating slicer on the plantain. It is made up of four units namely: Iron Framework, Power Unit, the Slicing Chamber and the Collection Unit.

- The framework: was made of low carbon iron, the stand from a rectangular shape. The stand supports and holds the machine component and gives it a compact design and study outlook.

- The power Unit: this comprises of an electric motor of $1 \mathrm{hp}$ with a speed of 1440 RPM and a capacitor. The machine is powered as soon as it is connected to an electric source.

- The plantain slicing unit: is on the frame work, mounted on the stand. The slicing unit is made up of stainless sheet. The slicing unit has a slicer within it and it is responsible for the slicing of plantain.

- Plantain cones: these are welded in a circular arrangement inside the housing. They are made of stainless steel and have diameters of 40 and $45 \mathrm{~mm}$ respectively in the housing. These cones help to hold the plantains ready to be sliced by the machine.

- Collection tray: It collects the sliced plantains from the slicing unit. The sliced plantains are passed to the collection tray through a hole cut in the slicing unit.

Plates 1 and 2 below give a pictorial view of the selected plantain slicers for this study:-. 


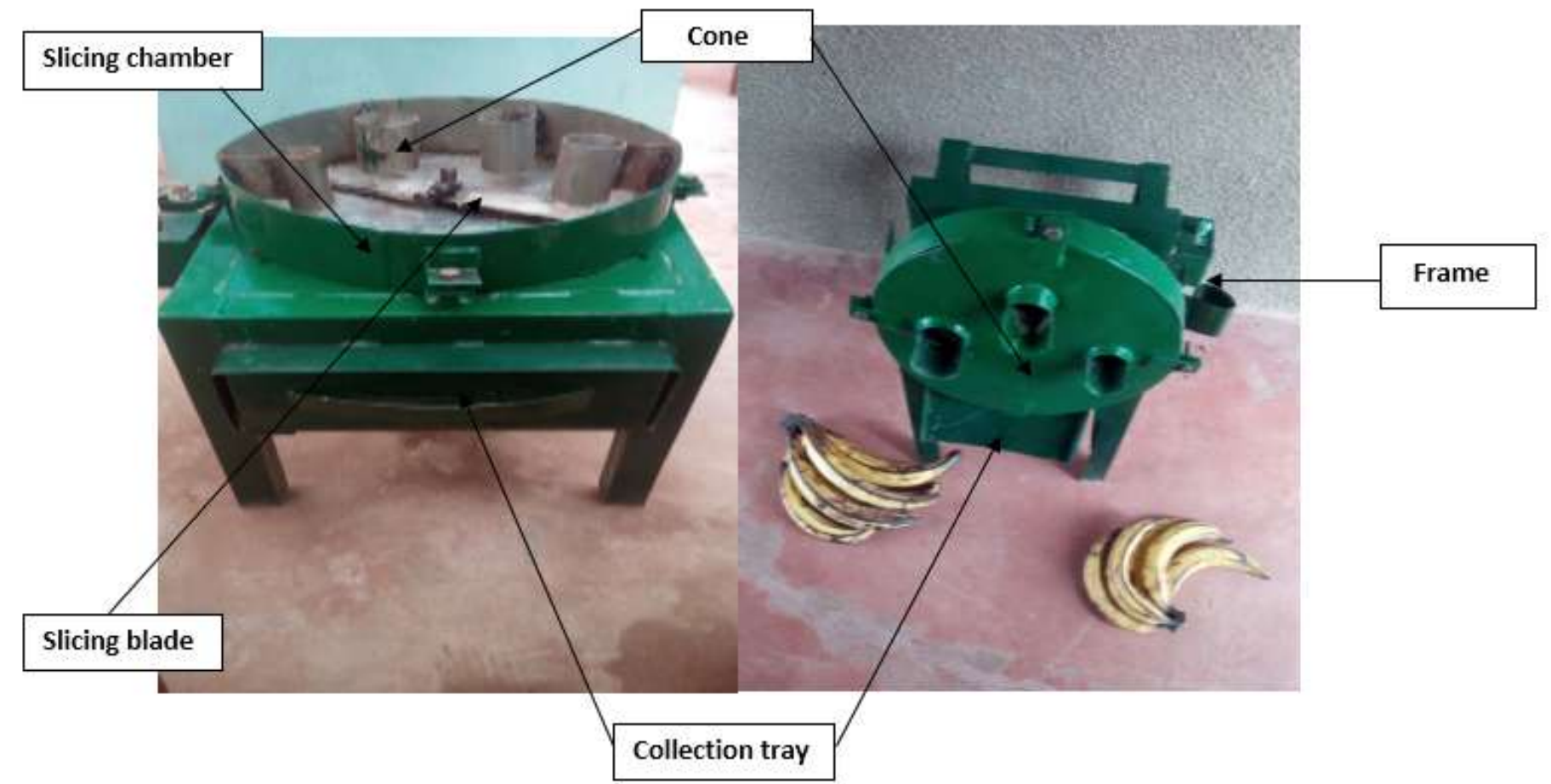

Plate 1: Horizontally inclined slicer

\section{Performance testing}

The electric motor was allowed to run for few minutes to study the behavior of the machines. Testing of the machines was then carried out with raw ripe plantains. The plantains were placed in the cones, the motor engine was started and the plantains were sliced in the shortest possible time. The lengths and diameters of plantains before slicing were taking note of, and the time for complete mass of fruit fed into the respective designs were recorded, evaluated and compared. Varieties of plantains with sizes 200, 230 and 250mm were sliced using the machines and replicate five (5) times. The results were recorded and the two (2) were compared.

\section{Evaluation parameters}

The parameters considered in comparing the selected plantain slicers include; shelling power, shelling speed, shelling force, throughput capacity and the efficiency of the machine.

Shelling speed (V) ... this is the rate at which plantain is sliced.

$$
\begin{aligned}
& \mathrm{V}=\omega \mathrm{r} \\
& \text { where } \\
& \begin{array}{l}
\omega \text {... } \\
\text { speed of motor } \\
\mathrm{r} \text {... radius of the slicing blade }
\end{array}
\end{aligned}
$$

Shelling force (F) ... this is the force exerted to slice plantain per time

$$
F=p / v
$$

Plate 2: Vertically inclined slicer

Throughput capacity $(\mathbf{K g} / \mathbf{h})$... Throughput is the rate of slicing; it is the quantity of sliced plantain divided by the time taken.

Throughput $=$ weight $/ t(\mathrm{Kg} / \mathrm{h})$

Where

Weight ... weight of sliced plantain

$t$... total time taken to slice

Efficiency (\%) ... The efficiency of the machine was calculated using the equation below:

Efficiency $=\left[\frac{\{W 1-W 2\}}{W 1}\right] \times 100$

where

$\mathrm{W} 1$... Total weight of plantain

W2 ... weight of damaged plantain

\section{RESULTS AND DISCUSSION}

\section{Result}

The selected slicing machines were horizontally inclined slicer (HIS) and vertically inclined slicer (VIS). These slicers were carefully chosen and it was ensured they had same power input, motor speed, and slicing blade of equal radius.

- $\quad$ Power capacity of electric motor $(\mathrm{P})=1 \mathrm{HP}$

- $\quad$ Speed $(\mathrm{N})$ of motor $=1440 \mathrm{Rpm}$

- $\quad$ Radius(r) of slicer $=12 \mathrm{~mm}$

Table 1 below gives the similarities between the power rating, the applied force and the slicing speed of the slicers. 
Table 1: Power rating, force and speed of the respective slicers

\begin{tabular}{|c|c|c|c|}
\hline Slicer & Power $(\mathbf{W})$ & Force $(\mathbf{N})$ & Speed $(\mathbf{m} / \mathbf{s})$ \\
\hline HIS & 746 & 414 & 1.8 \\
\hline VIS & 746 & 414 & 1.8 \\
\hline
\end{tabular}

The results of the throughput capacities are summarized in tables 2 and figure 1 below. The highest throughput capacity for HIS was 51.16 and had an average throughput capacity of $50.10 \mathrm{~kg} / \mathrm{hr}$ while the highest throughput capacity for VIS was
$45.90 \mathrm{~kg} / \mathrm{hr}$ and had an average throughput capacity of $45.34 \mathrm{~kg} / \mathrm{hr}$. Figure 1 clearly shows that HIS performed better than VIS in terms of throughput capacity.

Table 2: Throughput capacity

\begin{tabular}{|c|c|c|c|c|c|}
\hline \multicolumn{2}{|c|}{} & \multicolumn{3}{c|}{ VIS } \\
\hline Weight (kg) & Time (s) & Throughput (kg/hr) & Weight (kg) & Time (s) & Throughput (kg/hr) \\
\hline 2.55 & 185 & 49.62 & 2.55 & 200 & 45.9 \\
\hline 2.59 & 187 & 49.86 & 2.59 & 206 & 45.26 \\
\hline 2.55 & 184 & 49.89 & 2.55 & 205 & 44.78 \\
\hline 2.70 & 190 & 51.16 & 2.70 & 209 & 46.5 \\
\hline & & 50.10 & & & 45.34 \\
\hline
\end{tabular}

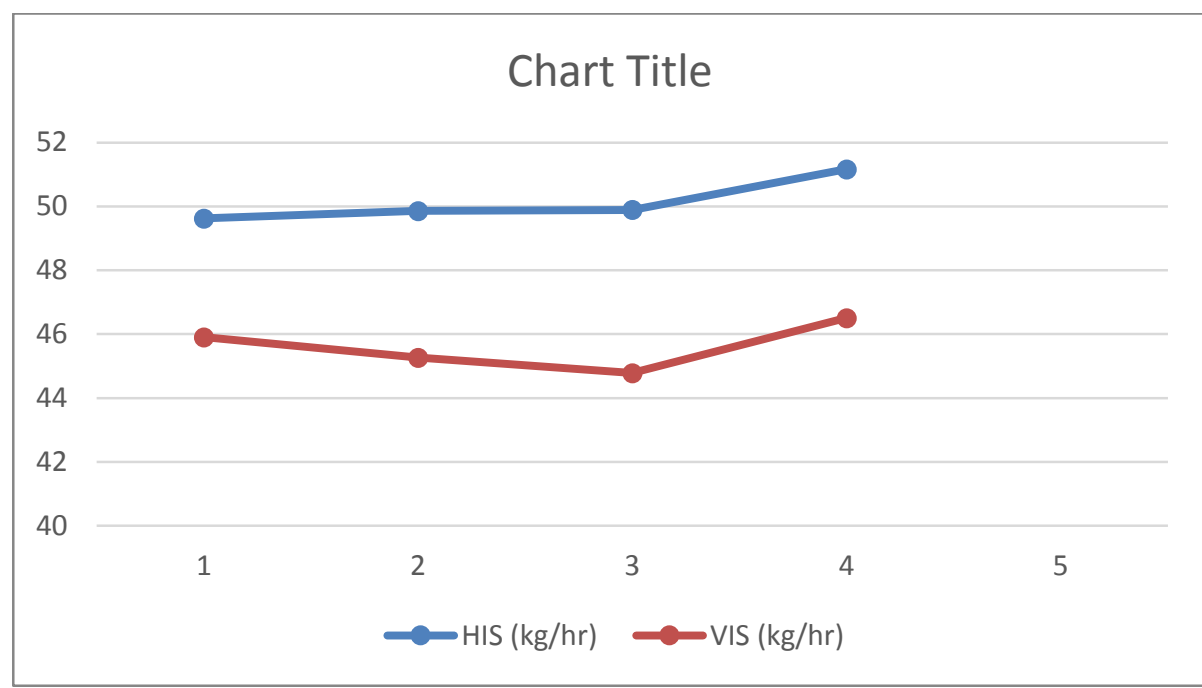

Figure 1: throughput capacity of HIS and VIS

The results of the slicing efficiencies are summarized in table 3 and figure 2 below. It shows that a maximum efficiency of $100 \%$ was obtained but had an average efficiency value of $92.84 \%$, while VIS had a maximum efficiency value of $87 \%$ and an average efficiency value of $83.25 \%$. Figure 2 suggests that HIS had a better efficiency for all the replicates, except for the third one where they were fairly equal.

Table 3: Slicing efficiency

\begin{tabular}{|l|l|l|l|l|l|}
\hline \multicolumn{2}{|l|}{ HIS } & \multicolumn{3}{c|}{ VIS } \\
\hline W1 (kg) & W2 $(\mathrm{kg})$ & Efficiency $(\%)$ & W1 $(\mathrm{kg})$ & W2 $(\mathrm{kg})$ & Efficiency $(\%)$ \\
\hline 2.55 & 0.00 & 100 & 2.55 & 0.52 & 80 \\
\hline 2.59 & 0.10 & 96.14 & 2.59 & 40 & 85 \\
\hline 2.55 & 0.33 & 87.06 & 2.55 & 0.33 & 87 \\
\hline 2.70 & 0.32 & 88.15 & 2.70 & 0.51 & 81 \\
\hline & & 92.84 & & & 83.25 \\
\hline
\end{tabular}




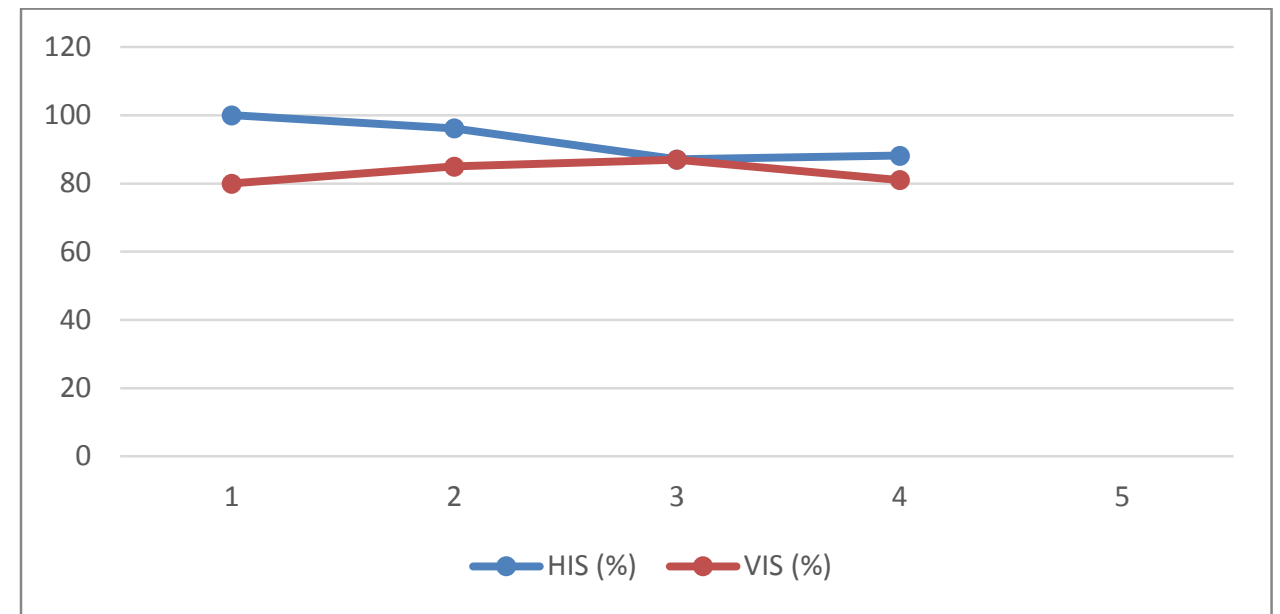

Figure 2: Efficiency of HIS and VIS

\section{CONCLUSION}

The two selected slicing machines were horizontally inclined slicer (HIS) and vertically inclined slicer (VIS). These slicers were carefully chosen and it was ensured they had same power input, motor speed, and slicing blade of equal length. The highest throughput capacity for HIS was $51.16 \mathrm{~kg} / \mathrm{hr}$ and had an average throughput capacity of $50.10 \mathrm{~kg} / \mathrm{hr}$ while the highest throughput capacity for VIS was $45.90 \mathrm{~kg} / \mathrm{hr}$ and had an average throughput capacity of $45.34 \mathrm{~kg} / \mathrm{hr}$.

The results of the slicing efficiencies showed that a maximum efficiency of $100 \%$, but had an average efficiency value of $92.84 \%$, while VIS had a maximum efficiency value of $87 \%$ and an average efficiency value of $83.25 \%$. From the results of the throughput capacity and the efficiency of the two slicers, it can be concluded that HIS performed better and faster than VIS.

\section{REFERENCES}

1. Awoliyi, O.O. (2003): "Design and construction of plantain slicer" unpublished thesis dissertation in Department of design and fabrication. Federal Institute of Industrial Research, Oshodi, pp 20-21.

2. FIIRO Federal Institute of industrial research (2008) Fabricated machines, available at http://www.fiiro.org/engineering/projects/plantaindetails

3. Food and Agricultural Organization of United Nation (1990). "root tubers, plantains and banana in human nutrition series, 24, Rome-Italy. pp 37-45.

4. IITA (international institutes of tropical agricultural (1996): a research report edited and

5. produced in the publication of IITA unit of the information service program IITA Ibadan,

6. Nigeria pp 20-22.

7. Nwanekezie, C and Ukagu, J.C. (1999).Nigeria food Journal, Vol. 17 pp. 55.

8. Obeng, G.Y. (2004): Design and fabrication and testing of a mechanized plantain and carrot slicer. Technology consultancy center Kwame Nkrumah
University of science for WestAfrican schools, Ghana, vol. 24, (2), pp126-133.

9. Okafor, B.E. and Okafor, V.C. (2013): Design of a plantain chips slicing machine, International Journal of Engineering and Technology, vol 3 (10) pp 928-932. 